\title{
First-Person Experiments: A Characterisation and Defence
}

\author{
Brentyn J. Ramm ${ }^{1,2}$
}

Published online: 17 February 2018

(C) Springer Science+Business Media B.V., part of Springer Nature 2018

\begin{abstract}
While first-person methods are essential for a science of consciousness, it is controversial what form these methods should take and whether any such methods are reliable. I propose that first-person experiments are a reliable method for investigating conscious experience. I outline the history of these methods and describe their characteristics. In particular, a first-person experiment is an intervention on a subject's experience in which independent variables are manipulated, extraneous variables are held fixed, and in which the subject makes a phenomenal judgement about the target experience of the investigation. I examine historical and contemporary examples of first-person experiments: Mariotte's demonstration of the visual blind spot, Kanizsa's subjective contours, the Tse Illusion, and investigations of the non-uniform resolution of the visual field. I discuss the role that phenomenal contrast plays in these methods, and how they overcome typical introspective errors. I argue that their intersubjective repeatability is an important factor in their scientific status, however, it is not the only factor. That they control for extraneous factors and confounds is another factor which sets them apart from pseudoscience (e.g., the perception of auras), and hence another reason for classifying them as genuine experiments. Furthermore, by systematically mapping out the structure of visual experience, these methods make scientific progress. Praises of such first-person experimental approaches may not always be sung by philosophers and psychologists, but they continue to flourish as respectable scientific methods nevertheless.
\end{abstract}

\section{Introduction}

My conscious experience is what I know most intimately. No one else can experience my sense of nostalgia when I think about building cubby houses as a child. Third-

Brentyn J. Ramm

brentynramm@gmail.com

1 School of Philosophy, HC Coombs, Building 9, The Australian National University, Canberra ACT 0200, Australia

2 Department of Philosophy, The Ohio State University, 350 University Hall, 230 N Oval Mall, Columbus, OH 43210, USA 
person scientific methods have been astonishingly successful in revealing the physical structures and dynamics of the world. Our conscious experience, however, has remained stubbornly baffling. One potential reason for this is that the phenomenal consciousness of another simply cannot be observed from the third-person perspective. I cannot literally open up someone else's brain and see their thoughts, feelings, imaginings etc. Third-person science could theoretically give a complete physical explanation of the world without ever invoking consciousness, suggesting that this paradigm is incomplete (Chalmers 1995). As conscious experience cannot be directly observed from the third-person perspective, a first-person approach is essential in any scientific investigation of consciousness.

Many have been pessimistic about this possibility. According to a number of philosophers and psychologists first-person methods are irredeemably fraught with sources of error (Dennett 1991, 2001; Irvine 2012; Lyons 1986; Nisbett and Wilson 1977; Piccinini 2010; Schwitzgebel 2011, Schwitzgebel in Hurlburt and Schwitzgebel 2007). In a particularly strong statement of this sceptical attitude, Daniel Dennett (2001) states, 'First-person science of consciousness is a discipline with no methods, no data, no results, no future, no promise. It will remain a fantasy'. Elizabeth Irvine also criticises a number of contemporary first-person methods and concludes that 'the persistent and ineradicable presence of bias in subjective measures... affects... all introspective methods' (Irvine 2012, p. 642).

Piccinini (2010, p. 102-103) criticises first-person methods on the grounds that subjects cannot control for their own biases and confabulations. Piccinini follows Dennett $(1991,2003,2007)$ in discounting the making of judgements about one's own experience (autophenomenology) as unscientific. Rather he holds that only an external experimenter can validly use a subject's reports as data and control for biases. Dennett refers to this third-person approach as 'heterophenomenology' (Dennett 1991, 2003, 2007). Concurring with much of Dennett's approach, Piccinini remarks, 'I couldn't agree more that lone-wolf autophenomenology - regardless of its heuristic value, which may well be significant - is no scientific method' (Piccinini 2010, p. 101). This has the consequence that standard practices in psychology are unscientific or at best pre-scientific. For example, it is a common practice for psychologists to self-pilot their experiments on themselves. Their experience of what it is like to do the experiment is often used to both alter the parameters of an experiment, and also to generate hypotheses about what other subjects are doing. In fact, the development of illusions would likely be impossible without the experimenter refining the illusions by testing 'what works' based upon their own experience. In contrast to heterophenomenology, I maintain that these autophenomenological practices should not be swept under the carpet but accepted as standard scientific practice in conjunction with intersubjective verification, data analysis etc. (Velmans 2007, p. 228). I will also be arguing, on the contrary to Piccinini that (within limits) first-person experiments can be used to control for a subject's own biases, errors and even to test hypotheses.

Are reliable first-person methods possible or are they just a fantasy as Dennett contends? No doubt there are many sources of first-person errors, however, thirdperson methods are also subject to many sources of error, which often require sophisticated methods to control. Taking further inspiration from science, we find that experiments are a particularly effective method for isolating variables of interest and for controlling for sources of error. Hence a potentially reliable first-person method would be to use a first-person equivalent of a standard scientific experiment in 
investigating questions about experience - 'first-person experiments'. Such methods have been proposed by Ginsburg (2005).

There have been many discussions of first-person methods used in conjunction with third-person methods (e.g., Lutz and Thompson 2003; Varela 1996; Jack and Shallice 2001) but few discussions of how to conduct experiments that take place entirely within the first-person perspective, nor how to distinguish such experimental methods from third-person experiments. One of my contentions will be that first-person experiments are in fact common and well-respected scientific methods. By ignoring them, critics of first-person methods give the misplaced impression that there are few reliable firstperson methods and certainly no such thing as first-person science.

The plan for the paper is as follows: In section 2, I outline the historical background of first-person experiments. In section 3, I seek to characterise what makes a method a first-person experiment, and how to distinguish these methods from third-person experiments. In section 4, I describe examples of first-person experiments for deciding what properties show up in perceptual experience. In section 5, I discuss the role of phenomenal contrast in first-person experiments. In section 6, I argue that first-person experiments overcome typical introspective errors. In section 7, I discuss the intersubjectivity of scientific methods. I make some concluding comments in section 8 .

\section{The Historical Origin of First-Person Experiments}

An early historical example of a first-person experiment was Edme Mariotte's discovery of the visual blind spot in 1668 (Grzybowski and Aydin 2007). The lens of the eye projects light onto the retina at the back of the eye. The optic nerve takes up a portion of the optic disc in the centre of the retina such that there are no photoreceptors at this location. The prevailing view at the time was that the optic nerve was the most light sensitive part of the eye. Mariotte tested this hypothesis by performing an experiment in which the light from an object was projected onto the optic nerve. He placed a small disc of white paper on a dark background at eye level, and a larger disc of four inches which he placed lower and to the right. He closed his left eye, and keeping his right eye fixated on the small disc he walked backwards. When he was approximately ten feet away the large disc disappeared. He repeated the experiment with his left eye and obtained the same result. Mariotte's discovery of a visual blind spot, which could only derive from the optic nerve, disconfirmed the prevailing view that the optic nerve was light sensitive. A variation on his experiment is below (see Fig. 1).

\subsection{Experiment 1: The Visual Blind Spot}

Close your left eye and with your right eye focus on the X. Maintain this focus and move your head towards the page until the $\mathrm{O}$ disappears. You have found the

\section{$\mathrm{X}$}

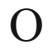

Fig. 1 The Visual Blind Spot Experiment. Close your left eye and focus on the X. Move forwards until the O disappears 
visual blind spot. Moving away and towards the page see how it appears and disappears.

This demonstration takes place in your first-person conscious experience - it is a firstperson experiment. The question asked in the experiment is not whether an $\mathrm{O}$ is always present or absent on the page as you move towards and away from it, but whether an $\mathrm{O}$ seems to be present at all distances. It is an experiment on the visual experience of $\mathrm{X}$ 's and O's. This finding substantiates the theory that the optic nerve is not receptive to visual stimulation. It also has extraordinary implications for how visual experience is constructed. The experience is that the $\mathrm{O}$ disappears but that there is not a hole in its place, rather the white background is 'filled in'. ${ }^{1}$ The experiment is replicable both within subjects at different times and across subjects (with the same eye anatomy). As long as I carefully follow the instructions, the phenomenon occurs whether I believe in it or not; it is not apparently affected by expectations. It is a reliable phenomenological experiment. $^{2}$

First-person experiments are to be distinguished from the typical methods of Introspective psychology which tended to rely upon extensive training of subjects to control for introspective errors rather than experimental manipulation. One of the reasons for the failure of Introspective psychology was reputably its inability to resolve the dispute over imageless thought (Boring 1953; Lyons 1986). Members of the Würzburg School claimed to find introspective evidence of imageless thought, while Titchener and his followers claimed the opposite. Neither could the schools agree on the number of sensory elements nor upon their basic attributes (though see footnote 11 below). In his famous behaviourist manifesto, John Watson (1913) criticised Introspective psychology for its inability to resolve such questions:

I firmly believe that two hundred years from now, unless the introspective method is discarded, psychology will still be divided on the question as to whether auditory sensations have the quality of 'extension', whether intensity is an attribute which can be applied to colour, whether there is a difference in 'texture' between image and sensation and upon many hundreds of others of like character. (Watson 1913, p. 164)

Although much of Introspective psychology involved the attempt to identify sensory elements through the extensive training of subjects (Danziger 1980), there were also examples of the use of first-person experiments. For example, one introspective method was to view two objects one at a time through a hole in a card so as to remove the influence of background. In this way an obliquely viewed plate would seem elliptical rather than circular. Similar methods were used to eradicate size and brightness constancy from experience and to thus arrive at the 'pure sensations'. Gestalt psychologist Wolfgang Köhler (1947) criticised these first-person experiments not due to their unreliability but due to their artificiality in attempting to exclude sensory context and

\footnotetext{
${ }^{1}$ Dennett (1991, p. 356) argues that the visual blind spot is not in fact filled in but rather ignored. See Churchland and Ramachandran (1994) for empirical evidence that filling in does occur.

${ }^{2}$ Helmholtz (1860/1925, p. 205-216) discusses a number of variations on this experiment.
} 
meaning from experience. Köhler remarked, 'when I apply the Introspectionist's methods I often find the same experiences as he does. But I am far from attributing to such facts a rare value as though they were more 'true' than the facts of everyday experience' (Köhler 1947, p. 52).

Phenomenology is an alternative first-person approach to Introspective psychology also with roots in early German experimental psychology. Beginning with Brentano, phenomenology split off into two main branches. Husserl developed philosophical phenomenology with followers such as Heidegger, Merleau-Ponty, and Sartre. In the second branch, Carl Stumpf initiated an experimental approach to phenomenology 'experimental phenomenology' (Vicario 1993). Stumpf's students, Wertheimer, Koffka and Köhler pioneered Gestalt psychology, in particular they used first-person experiments in the identification of laws of sensory grouping (Koffka 1935; Köhler 1947; Wertheimer 1912). Unlike the Introspective psychologists, the Gestalt psychologists emphasised the investigation of ordinary experience without the extensive training of subjects.

A first-person experimental approach is also found in the investigation of illusions (Kanizsa 1976; Müller-Lyer 1889). Hatfield (2005, p. 276-277) emphasises the important role that 'demonstration drawings' play in these investigations and how they continue to be used in perception textbooks for demonstrating phenomenological effects. Vicario remarks that, 'Gaetano Kanizsa used to say... that he performed his own experiments on the pages of his books' (Vicario 1993, p. 202). Figures that result in multi-stable perception such as the Necker cube are also examples of the use of demonstration drawings (see also, Ihde 2012). Many examples can be found in Robinson (2013), Rock (1975) and Palmer (1999). Furthermore, Julesz (1964) found that two images of random dots presented separately to each eye can create an impression of depth (stereopsis), hence demonstrating that illusions of depth can occur even in the absence of monocular depth cues. Another example of experimental phenomenology is Douglas Harding's use of experiments for investigating the first-person subject (Harding 1990/1999; Ramm 2017). For example, you are asked to point at where you seem to be looking from (where others see your face) and to judge whether what you are looking out of seems to be face-like or gap-like. A handbook dedicated to experimental phenomenology has also recently appeared (Albertazzi 2013).

\section{What is a First-Person Experiment?}

How can we characterise a first-person experiment? This question can be divided into two further questions: (1) What is a scientific experiment? and (2) What is a specifically first-person experiment?

A standard scientific experiment is often characterised as differing from 'mere' observation in that it involves an intervention on a system. In particular, an experiment involves an intervention on a system in order to observe the effect on properties of the system (Bogen 2010; Hacking 1983; Parker 2009; Tiles 1993; Woodward 2003). ${ }^{3}$ As Wendy Parker states it, 'an experiment can be characterized as an investigative activity that involves intervening on a system in order to see how properties of interest of the system change, if at all, in light of that intervention' (Parker 2009, p. 487). The

\footnotetext{
${ }^{3}$ See Meketa (2012) for criticism of the experiment-observation distinction in scientific practice.
} 
advantage of an experiment is that it can produce a predicted change/non-change in a dependent variable hence testing a hypothesis about that system. By putting the system into a novel state an experiment can isolate a property of interest and also be used to control for confounding background factors.

As an example, suppose I want to test the electrical conductivity of water that has sodium chloride dissolved in it. By setting up a circuit through a beaker of water and connecting it to a galvanometer it can be shown that the salt solution conducts electricity. This can be compared with distilled water which will not conduct a current. How different levels of sodium chloride affect conductivity can be tested by varying the amount of salt in the solution. By holding fixed other factors such as amount of water, water temperature, and distance of the electrodes from each other in the water, the effect of sodium chloride concentration on electrical conductivity can be isolated.

A first-person experiment then would involve an intervention upon a subject's experience. However, this fact by itself is not sufficient in distinguishing a firstperson experiment from a third-person experiment, since most experiments involve an intervention on a subject's experience. A subject's experience is systematically manipulated in most psychological experiments yet most investigations in psychology do not explicitly use first-person methods, such as experiments on concept acquisition and structure, short-term memory retention, visual search, semantic priming, and visual perceptual processing. The reason for this, I contend, is that most of these studies do not involve subjects making a judgement about their experience. For example, perceptual judgements, such as when a subject judges how long a line is in a display, involve judgements about the presented stimuli. On the other hand, if we were to ask how long the line looks then this would be a first-person method. Restricting first-person methods to those that involve phenomenal judgements has the advantage that not all experiments in psychology count as first-person experiments.

The experiment with the galvanometer relies upon an observer experiencing it, but it is not a first-person experiment. This is because my judgement is not about what it is like to see the galvanometer, but about the conductivity of the water. I make judgements about properties of the world based upon my experience of it in conjunction with background beliefs and theory. Call these judgements 'objectival judgements'. These third-person methods are distinguished from experiments in which I make a 'phenomenal judgement', that is a judgement about my present experience such as how things look, seem, and feel. For example, in looking at a wall through red coloured spectacles, I may judge that the wall looks pink (phenomenal judgement), or judge that the wall is white (objectival judgement). In the latter case, my belief that I am looking through red spectacles is used to infer beyond how things look. In other cases, in standard lighting and viewing conditions, I may judge that the wall both looks white (phenomenal judgement) and is white (perceptual judgement). ${ }^{4}$ In a perceptual judgment, I make a judgement about the world but I do not infer beyond currently perceptible properties. First-person experiments hence have a clearly distinguishable subject matter from third-

\footnotetext{
${ }^{4}$ This example is complicated by the question of whether colours are mind-independent properties of the world or mind-dependent properties. If colours are considered to be mind-dependent then the judgement would be about the way the world normally looks under certain conditions, as opposed to the world of physics, hence the distinction between phenomenal and perceptual judgements would break down. For the purposes of this example, the actual metaphysics of colours does not matter only what the subject believes; here I have in mind a subject that believes a version of naïve realism.
} 
person experiments. In particular, the target of the judgement differs between thirdperson and first-person experiments.

An objection to counting the Mariotte's blind spot experiment as a first-person experiment is that the judgement could merely be about whether a disc is perceptually present to one or not at a certain distance. That is, it is a perceptual presence/ absence judgement rather than a phenomenal judgement. Suppose Mariotte had thought to himself, 'I do not see a disc at ten feet'. This judgement does not explicitly refer to visual experience. However, not all judgements about experience explicitly use terms like 'looks' and 'seems'. Given Mariotte's background beliefs, it is plausible that his thought is an implicit phenomenal judgement. ${ }^{5} \mathrm{He}$ was not interested in whether a disc was in fact present or absent in the world - that would have been a perceptual judgement. Since he assumed that the disc was present at all times, his thought cannot have been about the presence or absence of the disc. Neither was he interested in whether he unconsciously saw the disc, otherwise his test would have been inconclusive. Rather he was interested in whether he consciously visually experienced a disc or not at all distances of observation. Hence, even if Mariotte had not explicitly made a judgement about whether he seemed to see a disc or not, that it was intended to be a phenomenal judgement can be reconstructed from his other assumptions.

Based upon the considerations discussed above, an initial characterisation of a firstperson experiment is:

(1) An investigative activity in which there is an intervention on a subject's experience and the subject makes a judgement (implicitly or explicitly) about the resulting phenomenal experience.

A clarification of this characterisation is that the intervention on the subject's experience could be made by the investigator themselves such that they intervene on their own experience, or by an investigator who is not the subject.

A problem with the above characterisation is that it is too unconstrained. If I imagine a house and then make a judgement about it, this will fit the criteria for being a firstperson experiment. The mere act of imagining changes experience in that there is now a visual image where before there was not, and hence involves an intervention upon experience. However this does not involve enough constraints to count as an experiment. An experiment needs to include an effort to manipulate some properties, while keeping others fixed. A more restrictive characterisation then is:

(2) An investigative activity in which there is an intervention on a subject's experience in which independent variables (phenomenal or non-phenomenal) are manipulated, and extraneous variables (phenomenal or non-phenomenal) are held fixed, and in which the subject makes a judgement (implicitly or explicitly) about the target experience of the investigation (dependent variable).

In Mariotte's experiment the dependent variable was whether or not there seemed to be a large disc in front of him. The independent variable was the distance at which he

\footnotetext{
$\overline{5}$ Thank you to Jérôme Sackur and an anonymous reviewer for highlighting the importance of this distinction.
} 
viewed disc. He held fixed other factors such as binocular vision by closing one eye, and the direction of focus by fixating on the small disc. The example of imagining a house by contrast does not involve the manipulation of any independent variables.

Such first-person experiments can be distinguished from experiments in which the subject plays a more passive role. For example subjects may rate the vividness of their mental images in high working memory load and low working memory load conditions. The experimenter will then typically test the hypothesis about how the vividness of mental imagery interacts with working memory load by statistical methods. Here the critical comparison which tests the theory is done by the experimenter, outside of the subject's experience. In Mariotte's experiment, on the other hand, the subject themselves make the critical judgement for testing the theory. These are the types of experiments that I will focus on here. Although both are experiments which involve phenomenal judgements, I will reserve the term 'first-person experiments' for the latter type of first-person methods.

\section{Further Examples of First-Person Experiments}

\subsection{Experiment 2: Subjective Contours}

On the above characterisation there is little doubt that there can be, and in fact are, numerous first-person experiments. A classic example of a first-person experiment comes from the investigation of 'subjective contours' by Kanizsa (1976). These experiments provide a systematic investigation of how context changes experience.

\section{a}
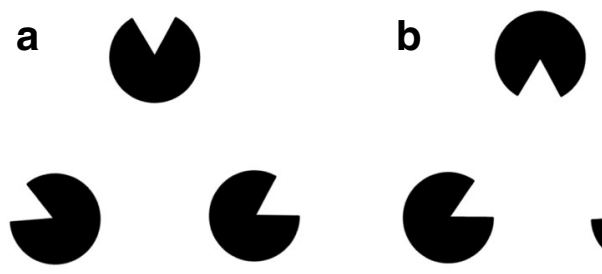

b

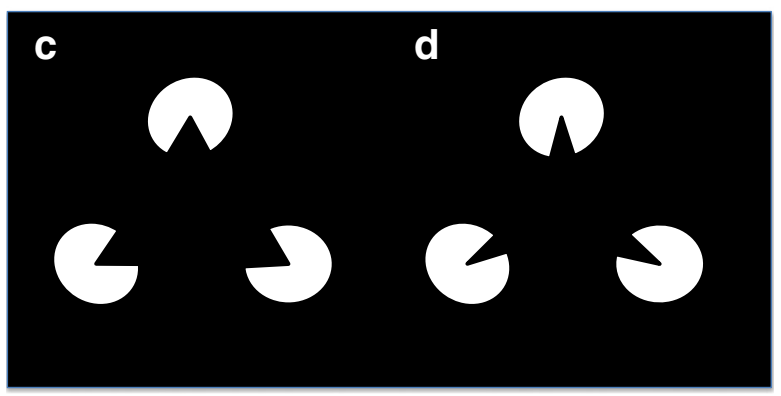

Fig. 2 Subjective Contours. A phenomenal contrast between A and B demonstrates that changes in spatial organisation can lead to emergent shape phenomenology, in particular a triangle in B but not in A. Subjective contours also occur with a black background in $\mathrm{C}$ and $\mathrm{D}$, and non-straight contours in $\mathrm{D}$ 
Using the depicted images in Fig. 2, one can test the hypothesis that changes in spatial organisation can lead to emergent phenomenal character. The images in $\mathrm{A}$ and $\mathrm{B}$ show two groups of black pie-shapes. The only difference between the A group and B group is the spatial orientation of the shapes (the independent variable). There is an additional type of phenomenal character in experiencing $\mathrm{B}$ which is not present in experiencing $\mathrm{A}$, that of seeing a triangle (the dependent variable). I see lines connecting the shapes where there are none.

This experiment supports the hypothesis that changes in spatial organisation can lead to emergent or gestalt phenomenology. Further questions arise such as whether such phenomenal shapes occur with different coloured backgrounds and pie-shapes. This can be explored by manipulating these variables. Thus for instance, it is found that subjective contours also occur when the background is black as in $\mathrm{C}$, and that the apparent lines do not need to be straight as in D. By manipulating variables one can systematically investigate the conditions under which the phenomenon occurs (see Kanizsa 1976 for further conditions in which subjective contours manifest).

\subsection{Experiment 3: Attention and Subjective Brightness}

Another example of a first-person experiment is the Tse Illusion as illustrated in Fig. 3 (Tse 2005):

Look at $\mathrm{A}$ and fixate on one of small squares. Now shift attention to one of the discs. The perceived brightness of the attended disc decreases. It seems darker. This demonstrates that attention can change subjective brightness. Repeat this for $\mathrm{B}$ and notice that the effect is absent.
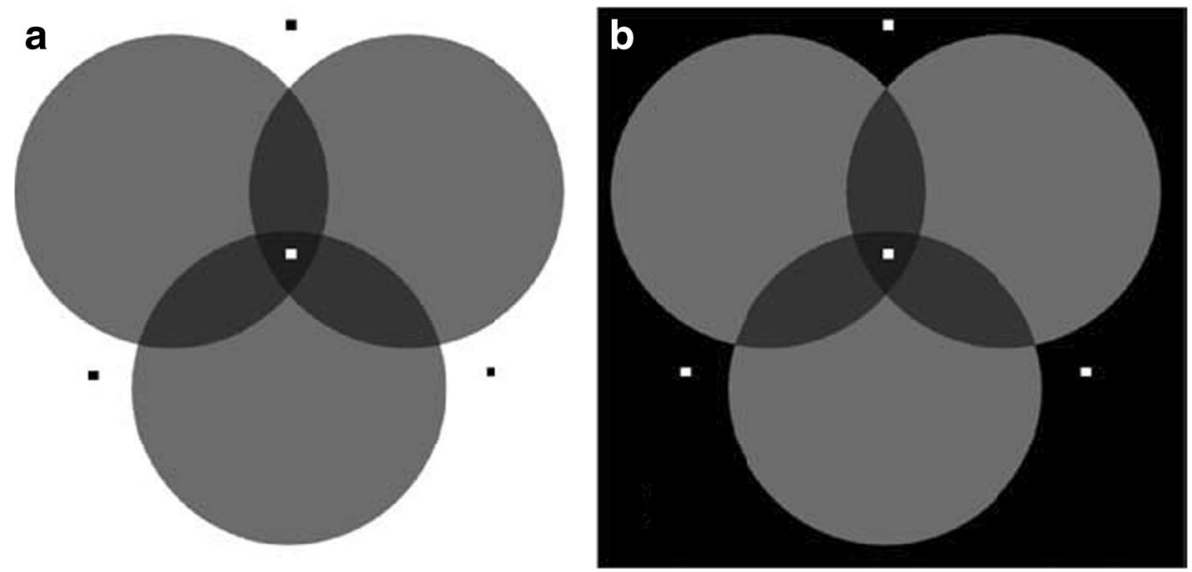

Fig. 3 The Tse Illusion. In A, focusing on a square and attending to a disc decreases the brightness of the attended disc. The effect is absent in B. Reprinted from Vision Research, 45(9), Tse, P. U., Voluntary Attention Modulates the Brightness of Overlapping Transparent Surfaces, p. 1096, Copyright 2005, with permission from Elsevier 
The effect plausibly stems from the visual system interpreting the discs as transparent. This explanation is supported by B where the effect is absent. Here the discs are overlaid on a black background, which removes an important cue indicating that the discs are transparent. This is hence another example in which identifying the circumstances in which a perceptual experience occurs illuminates the underlying perceptual mechanisms.

This is a first-person experiment because it involves subjects making a judgement about how bright the discs look (dependent variable), rather than how bright they actually are. It also involves holding fixed variables such as colour, shape and eye focus, while manipulating attention to different discs (independent variable). In $\mathrm{A}$ the decrease in subjective brightness for an attended disc involves the experience of a phenomenal difference between the attended and non-attended discs. In B, on the other hand, there is no phenomenal difference in brightness between attended and non-attended discs. The presence of the effect in A but not in B shows a further phenomenal difference. These experiments systematically manipulate attentional focus and background colour, while holding other factors fixed (see Tse (2005) for a manipulation of further factors).

\subsection{Experiment 4: The Visual Periphery}

We often think of our visual field as being like a television screen and hence uniform in resolution. In particular, we fail to notice that its clarity quickly drops off outside of central vision. This can be tested with the following experiment:

Hold out a single finger and focus your eyes on it. Now hold a hand up in your peripheral vision so that it is at the same depth as your finger. Now without moving your eyes attend to your hand. How many fingers can you distinguish? I find that it looks pink and blurry. I seem to have somewhere between four and five fingers, and there is no clear boundary where one finger ends and the next begins. Now look directly at your hand and see by contrast that the two appearances of your hand are radically different. The same applies to all objects seen peripherally and in the centre of your vision. In the centre objects seem distinct and in the periphery they seemingly blur together.

This provides an example of using a method of phenomenal contrast to notice my visual experience, and the use of apparatus (my hands) to assist in doing so. In a variation of this experiment, Dennett (1991, p. 53-54) suggests a method for investigating the degree to which the visual field is non-uniform in resolution. He suggests the observer focus on a central location, and then picking cards from a deck, hold them in varying locations to see at what point one recognises the colour, suit and number of the card. This illustrates a more fine grained use of the method of contrast (can I distinguish the number of the card or not in different locations?), and the use of apparatus for making the observations more precise (namely the playing cards). To make the experiment even more precise, instead of playing cards one could view a computer screen with a central fixation point which randomly displays letters (e.g., a T or an L) of different colours (e.g., red or blue) in different locations to see where I can most reliably 
identify the colour or the letter. ${ }^{6}$ Such experiments provide systematic and reliable means of mapping out the structure of visual experience. ${ }^{7}$

\section{Phenomenal Contrast}

Many first-person experiments (but not all) use a method of phenomenal contrast (Bayne 2009; Bayne and Montague 2011; Kriegel 2007; Masrour 2011; Siegel 2007; Robinson 2005). Rather than asking whether a plate viewed obliquely looks elliptical, one asks whether its shape looks different to the shape of a plate viewed straight on. That is, one looks for a phenomenal difference, thus allowing for a more refined phenomenal judgement. The critical test for whether phenomenal character differs between two scenarios is whether there is a phenomenal difference (Siewert 1998, p. 219).

First-person experiments are intrasubjective methods which often involve a subject making a phenomenal contrast between two target phenomena. These intrasubjective phenomenal contrasts can be distinguished from theoretical phenomenal contrasts. As an example of the latter, Bayne (2009) considers the phenomenal difference in what it must be like to have visual agnosia in which objects are not recognised and what it is like to have normal visual recognition of objects. This is a thought experiment rather than a first-person experiment. By thinking about two cases I come to believe that there must be a difference between the two types of experience (for other examples of theoretical phenomenal contrasts see Kriegel 2007). On the other hand, an intrasubjective contrast involves experiencing the phenomenal difference for oneself, either simultaneously or by contrasting a current experience with a recalled experience.

In experiment 1, the phenomenal contrast is between the apparent visual presence or absence of the disc. Perceiving that there is a distance at which the disc apparently disappears is necessary for demonstrating that there is a visual blind spot. In experiment 3 the phenomenal contrast in apparent brightness is made between attended discs and unattended discs. The attended disc looks darker than the unattended disc. The phenomenal contrast is required for isolating the phenomena. Without the contrast it would have been difficult to recognise that any change in apparent brightness had occurred at all. The Kanizsa triangle, on the other hand, provides an example where phenomenal contrast is not essential to the experiment. One does not need to use

\footnotetext{
${ }^{6}$ For other versions of the experiment see Hill (2011, p. 27) and Schwitzgebel (2011, p. 125-127).

${ }^{7}$ Irvine (2012) criticises these methods for not being significantly different from third-person methods. Indeed the only difference between the methods is whether subjects are making a judgement about the stimuli (perceptual judgement) or about their experience (phenomenal judgement). Irvine proposes: 'It could be argued that asking if an object appears clear to me is just to ask how precisely I can discriminate it, and how confident I am in my judgments about it. That is, objects may appear clear if I can confidently detect exactly where their edges are, if I can identify the patterns on its surface, and so on. If this is the case, is not immediately clear if trained introspective reports can add to the body of already existing behavioural evidence about the boundaries of conscious experience' (Irvine 2012, p. 633). The problem with this analysis is that things seem unclear in the visual periphery whether or not I am making a judgement about them. How things seem hence does not reduce to discriminative capacities. On the face of it, the difficulty in discriminating shapes in the periphery of vision is because they look blurry. Irvine's proposal seems to get the explanation backwards. That is, typical visual discriminations depend upon visual experience (for further arguments along these lines see Horst 2005). This would explain why in such cases first-person and third-person methods obtain virtually identical results.
} 
phenomenal contrast to see the subjective contours. However, making a contrast can tell us something, in particular that the figures are not deceptions. Perhaps I have drawn in very faint lines between the pie-shapes. By making the contrast it can be demonstrated that it is the change in spatial organisation that leads to the phenomenology in B, $\mathrm{C}$ and $\mathrm{D}$ but not in $\mathrm{A}$, and no tricks have been played. Another way of performing the contrast is to occlude two of the pie-shapes. When I do so the apparent connecting lines disappear.

\section{On the Unreliability of First-Person Methods}

Schwitzgebel (2011) presents a large number of problem cases to motivate the conclusion that naïve introspection is unreliable. ${ }^{8}$ Naïve introspection is the formation of phenomenal judgments without the assistance of training, apparatus, or any other methods. One of the primary aims of using a first-person experiment is to avoid or at least reduce errors in making phenomenal judgements. I previously categorised the errors in Schwitzgebel's cases and identified two main errors in making phenomenal judgements: attentional and conceptual (Ramm 2016). ${ }^{9}$ We make errors either because we fail to attend to the target experience or because there is a failure in possessing, forming or employing the correct phenomenal concept about the target (or both). For example, I may make erroneous judgements about the flavour of wine because I am not adequately attending to the flavours or because I do not possess adequate concepts (or both). Solomon (1990, p. 509) found that novices used the term 'bitterness' to describe 'sourness,' 'acidity' and 'level of tannins' (puckeriness) in a wine, while experts differentiated between these dimensions and were better at ranking wines on these dimensions.

It is a goal of first-person methods to control for these main sources of error. ${ }^{10}$ In particular, the methods are used to orient attention to the experienced properties, as well as providing a salient sample of an experience, so that a phenomenal concept can be activated or formed.

While naïve introspection can frequently go wrong, first-person experiments provide methods for overcoming these common errors. Experiment 3 assists subjects in controlling their attention by asking them to keep their eyes fixated on one of the squares and then shifting their attention to one of the discs at a time. Similarly in experiment 4 , keeping your eyes focused on a fixed point avoids the error of moving your eyes. This may be one of the main reasons that subjects typically do not notice the extent of the low resolution of the visual periphery (Schwitzgebel 2011, p. 126).

Experiments 2-4 provide a phenomenal sample of the target phenomena of interest. I experience the darkening of a disc when I attend to it, while all other factors are held constant. This succeeds in isolating the effect of attention changing subjective brightness. Although I probably had no concept of a subjective contour before looking at a diagram such as in fig. 2, doing so provides just such a sample phenomenal character.

\footnotetext{
${ }^{8}$ For defences of the reliability of introspection see: Bayne and Spener (2010), Kriegel (2013), Hohwy (2011), Ramm (2016), Peels (2016), Smithies (2013), Watzl and Wu (2012).

${ }^{9}$ See also Watzl and $\mathrm{Wu}(2012)$.

${ }^{10}$ For defences of first-person methods in a science of consciousness, see Goldman (2004), Hatfield (2005), and Shear and Verela (1999).
} 
By providing a sample of the property of interest the appropriate phenomenal concept can be activated or formed, hence the probability of making a conceptual error becomes very low.

A common criticism of first-person methods has been the occurrence of unresolvable intersubjective disagreements, such as Introspective psychology's imageless thought controversy and disagreement over the number of discriminable sensations (Boring 1942, 1953; Lyons 1986; Watson 1913). ${ }^{11}$ In recent times, the method of phenomenal contrast has also been criticised on the grounds that it often does not resolve the dispute it was meant to resolve (Bayne and Montague 2011, p. 22-23; Koksvik 2015; Nanay 2012). For example, phenomenal contrast by itself does not answer questions of high-level perception such as whether the category 'banana' shows up in perceptual experience. Philosophers continue to disagree (Siegel 2011, chapter 4; Prinz 2013; Siegel 2013).

Even if a phenomenal contrast does not by itself resolve the debate over categorical properties, the contrast is essential for isolating the experience that is to be explained. Susanna Siegel provides the example of a subject who learns to perceptually distinguish pine trees from other trees. She holds that for the subject who has gained this expertise, there is a phenomenal difference between their current and previous perceptual experience of pine trees. In their debate both Siegel and Prinz (Siegel 2011, chapter 4; Prinz 2013; Siegel 2013) agree that this phenomenal difference exists, so the firstperson method at least succeeds in fulfilling the limited purpose of isolating the phenomena of interest. According to Siegel:

The method of phenomenal contrast is a way to limit the use of introspection in theorizing about visual experience. All that introspection is relied upon to do is to detect the phenomenal contrast. The method need not take a stand on the category of the phenomenally contrasting states, such as whether they are sensory, cognitive or some other kind. (Siegel 2007, p. 139)

Hence it is consistent with a first-person method being reliable that subjects disagree about how to interpret their experiences.

Even if disagreements often occur for high level phenomena such as categorical properties, the results are often more clear cut for cases of lower level perceptual experiences. The results of the experiments presented here provide examples where there is high intersubjective agreement. That subjects experience subjective contours when viewing images such as in fig. 2 has been replicated on numerous occasions. In viewing the Tse Illusion all 16 subjects reported that the discs in A looked darker when

\footnotetext{
${ }^{11}$ A quibble over history: A popular illustration of the fatal disagreement between Introspective schools has been to cite Boring (1942), as reporting that Külpe's laboratory found less than 12,000 discriminable sensations, while Titchener's laboratory discovered more than 44,435 (e.g., Guzeldere 1995, p. 39; Nahmias 2002 , p. 6; Velmans 2000 , p. 48-49). This is an apparently very large disagreement. However these numbers exaggerate the difference because the 44,435 was the total number from Titchener's laboratory, while the 11,916 from Külpe's laboratory is the sum of the numbers provided by Boring. Boring does not actually provide the number of smells identified by Külpe - he merely says that he discovered 'numerous smells' (Boring 1942, p. 10). This unspecified number is in addition to the sum of 11,916 , so there is no way of calculating the actual total of sensations from Külpe from the numbers provided by Boring. The only numbers that are directly comparable are tastes (each laboratory identifying 4), and tones which was 11,063 for Külpe and 11,600 for Titchener. These are hardly large differences.
} 
they were attended (Tse 2005, p. 1096). All 16 subjects also reported no darkening of the discs in B when they were attended (ibid.). Upon conducting a test like experiment 4 , everyone will agree that peripheral vision is low in detail, perhaps to a far greater extent than they had previously realised.

While first-person experiments produce more refined judgements than unaided (naïve) phenomenal judgements, there is still room for disagreement. Assuming that the method supplies the same results across subjects, there is still the possibility of disagreement over how to interpret the phenomenal outcome. However, this does not necessarily undermine the reliability of the method. An example was the dispute amongst Introspective psychologists over imageless thought. This case is often used as evidence that first-person methods are unreliable. Monson (1993) however argues that the raw data obtained from subjects within the different labs was actually very similar. Rather the important difference was that each school coded the raw data differently depending upon their theoretical commitments. The introspectors were not unreliable, rather it was the experimenters themselves who produced the disagreement in the form of a theoretical dispute. ${ }^{12}$

\section{First-Person Methods and Publicity}

Scientific methods should be intersubjectively reliable, that is, they should in principle produce results that are repeatable by other observers with the same capacities in similar conditions (Dennett 1991, 2003, 2007; Piccinini 2003, 2009, 2010). ${ }^{13}$ Experiments 1-4 certainly meet this criterion for being scientific. Subject's experiences are private, however, first-person methods should be publically accessible in the sense that the same types of experiences can be reliably produced under similar conditions by different subjects. Phenomenal judgements are also a source of first-person data (records about experience). As first-person data is intersubjectively accessible it is also public. $^{14}$

\footnotetext{
${ }^{12}$ In a reviewer comment, Jérôme Sackur argues that it is an empirical question whether or not a specific experiment will convince a scientific community and hence be considered 'scientific'. I agree that establishing community consensus is important in scientific practice, however, I do not think that it reductively defines what is scientific. The theoretical dispute between Titchener's and Külpe's laboratories provides a case where community consensus did not seem to track the reliability of the methods in question. The different methods of each school converged on the same findings (an indicator of scientific reliability) and yet theoretical bias prevented the forming of a community consensus.

${ }^{13}$ Dennett $(1991,2003$, 2007) classifies methods by whether they are private (first-person) or public (thirdperson). Dennett's interchangeable use of 'third-person methods' and 'public methods' obscures the fact that all 'third-person observations' are made from a first-person perspective. There are no third-person observations, just first-person observations, and all first-person observations are private (Velmans 2000, chapter 8). I observe the star by experiencing it, and my experience is private. I do not have access to your experience of the star. Nevertheless each experience has a common cause (the star) and each of us can verify the other's experience when suitably positioned. In this sense the observation is public - that is, intersubjectively repeatable. As all observations are irreducibly subjective, the division between 'objective' and 'subjective' methods is a false dichotomy (ibid.). I take this fact into account by classifying an approach as a first-person method when it involves the observer making phenomenal judgements.

${ }^{14}$ Chalmers (2004, p. 1117) and Goldman (1997) use 'first-person data' to refer to phenomenal experience, hence entailing that it is private. Here, I follow Piccinini's (2009) usage of 'first-person data'.
} 
Perhaps the methods discussed in this paper should be excluded from being called genuine experiments because they involve the investigator's judgements about their own experience (autophenomenology). Why, however, should Mariotte's phenomenal judgements need to be verbalised and used by someone else for them to become a valid source of data? Critics of first-person methods maintain that subjects cannot control for their own biases and errors (Dennett 1991, chapters 3 and 4; Irvine 2012; Piccinini 2010; Schwitzgebel 2011), however, that this applies to all first-person methods is the very point that I have disputed.

Intersubjective reliability is of course an essential component in science, and an important check on the reliability of a method and for overcoming individual biases. Indeed, had Mariotte's method failed to replicate across subjects with the same eye anatomy he would have had a good reason to question his hypothesis as to the causal basis of the lack of visual experience in this location - namely, the existence of a perceptual blind spot built into the anatomy of the eye. On the other hand, his systematically recurring visual experience of the disc seeming to disappear in very specific viewing conditions would have remained a genuine phenomenological reality in need of explanation.

Perhaps the methods discussed here should be considered scientific only because they have been replicated by multiple subjects - before this they were pre-scientific. However, this constraint would rule out too many experiments in the third-person sciences where it is impractical to repeat an observation, such as a lone astronomer making an observation of a unique cosmic event. An observation only needs to be publically repeatable in principle for it to count as scientific; that is, if someone else had been there they could have made the observation and obtained the same results (Piccinini 2011, p. 106-107).

Piccinini (2011, p. 105-107) argues that without the constraint of intersubjective repeatability the perception of auras (energy fields surrounding people's bodies) would count as scientific. 'Auras' are purportedly reliably observed for claimed aura perceivers, but as Piccinini points out the perception of auras cannot be reliably replicated by unbiased subjects. Perhaps then the first-person procedures discussed here are scientific only because they are repeatable for other subjects.

It is illustrative to see how the case of auras contrasts with first-person experiments. Even setting aside their intersubjective reliability, the above methods are also scientific in another important sense - they control for extraneous factors and confounds. When a method adequately controls for extraneous factors and confounds it has internal validity (Campbell and Stanley, 1966). ${ }^{15}$ By contrast, it is doubtful that those that claim to perceive auras have adequately established the validity of their methods. For instance, they do not control for other simpler explanations for their experiences such as visual illusions, visual imagery, and visual afterimages. One study found 'aura perceivers' to be at chance at identifying the correct number of people in a totally dark room (Loftin 1990). This finding suggests that 'aura experiences' are unusual visual phenomena rather than the experience of energy fields. Such a test can undermine the aura hypothesis within the experience of a single subject even in the absence of a test for intersubjective reliability. Repeatability between subjects is not the only way to control for biases and confounding factors; hence, classifying systematic well-controlled

\footnotetext{
$\overline{{ }^{15} \text { A method has external validity }}$ when its results reliably generalise to other subjects and populations.
} 
investigations of one's own experience as experiments does not, on the face of it, threaten the distinction between science and pseudoscience.

\section{Conclusion}

By what methods should we investigate conscious experience? I suggested that firstperson methods are essential in any rigorous approach to consciousness, and that firstperson experiments have proved to be one such reliable first-person approach. I characterised first-person experiments and how they differ from third-person experiments. I also discussed a number of examples of these first-person experimental methods and how they overcome common introspective errors. These systematic investigations map out the structure of visual experience, in particular, by demonstrating: the existence of a visual blind spot, the conditions under which contour and brightness illusions occur, and the degree of the non-uniform resolution of the visual field. These discoveries represent genuine scientific progress. More controversially, by controlling for extraneous and confounding factors, these methods could be considered scientific even when they are only carried out by a single subject.

Although I have focused on first-person approaches to conscious experience this is not to deny the importance of third-person methods. A source of third-person data (records about the physical world) is a person's response time in judging how things look. This gives an insight into the duration of their underlying cognitive and perceptual processes. A difference in response time between conditions provides evidence that different processes are being employed. Other sources of third-person data are measures of physiological responses such as heart rate, skin conductance, and the electrical activity of the brain. First-person and third-person methods provide complimentary data; it is not a matter of choosing between them. Both approaches provide vital and mutually irreducible data in a science of consciousness (Chalmers 2004, p. 1112; Price and Barrell 2012, p. 278; Velmans 1991, p. 667).

The first-person experiments presented here allow for the testing of hypotheses about perception and perceptual experience, and produce reliable results over many occasions both within subjects and across subjects. In fact, numerous first-person experiments such as these have been in use since the late nineteenth century and continue to be used to investigate perceptual illusions and many other phenomena (Albertazzi 2013).

Of course, not all first-person experiments are successful, but this is also true of third-person experiments. The important fact is that many first-person experiments are reliable. This is a needed balance to the scepticism of first-person methods professed by many philosophers and psychologists (Dennett 1991, 2001; Irvine 2012; Lyons 1986; Nisbett and Wilson 1977; Piccinini 2010; Schwitzgebel 2011, Schwitzgebel in Hurlburt and Schwitzgebel 2007). A critical stance is laudable, and scepticism is well deserved for many first-person methods, but neither should we ignore the reliable first-person methods that do exist. Contrary to Dennett (2001) we can conclude that first-person science not only exists, but plays an indispensable role in psychology. Praises of first-person experimental approaches may not always be sung by philosophers and psychologists, but they continue to flourish as respectable scientific methods nevertheless. 
Acknowledgements I am grateful to David Chalmers, Declan Smithies, and Daniel Stoljar for helpful comments on the manuscript. Thank you also for reviewer comments from Jérôme Sackur and an anonymous reviewer, both of whose comments helped to significantly improve the manuscript.

\section{References}

Albertazzi, L. 2013. Handbook of experimental phenomenology: Visual perception of shape, space and appearance. Chichester: Wiley-Blackwell.

Bayne, T. 2009. Perception and the reach of phenomenal content. The Philosophical Quarterly 59: 385-404. Bayne, T., and M. Montague, eds. 2011. Cognitive phenomenology: An introduction. Oxford: Oxford University Press.

Bayne, T., and M. Spener. 2010. Introspective humility. Philosophical Issues 20 (1): 1-22.

Bogen, J. 2010. Theory and observation in science. In E. N. Zalta (Ed.), The Stanford Encyclopedia of Philosophy. URL = <http://plato.stanford.edu/archives/spr2010/entries/science-theory-observation/>.

Boring, E.G. 1942. Sensation and perception in the history of experimental psychology. Appleton-Century: New york.

Boring, E.G. 1953. A history of introspection. Psychological Bulletin 50 (3): 169-189.

Campbell, D.T., and J.C. Stanley. 1966. Experimental and quasi-experimental designs for research. Chicago: Rand McNally \& Company.

Chalmers, D.J. 1995. Facing up to the problem of consciousness. Journal of Consciousness Studies 2 (3): 200-219.

Chalmers, D.J. 2004. How can we construct a science of consciousness? In The Cognitive Neurosciences III, ed. M.S. Gazzaniga, 1111-1120. Cambridge: MIT Press.

Churchland, P.S., and V.S. Ramachandran. 1994. Filling in: Why Dennett is wrong. In Consciousness in Philosophy and Cognitive Neuroscience, ed. A. Revonsuo and M. Kamppinen, 65-91. Hillsdale: Laurence Erlbaum Associates.

Danziger, K. 1980. The history of introspection reconsidered. Journal of the History of the Behavioral Sciences 16 (3):241-262.

Dennett, D.C. 1991. Consciousness explained. Boston: Little, Brown and Company.

Dennett, D.C. 2001. The fantasy of first-person science, from http://ase.tufts.edu/cogstud/papers/chalmersdeb3 dft.htm.

Dennett, D.C. 2003. Who's on first? Heterophenomenology explained. Journal of Consciousness Studies 10 (9-10): 19-30.

Dennett, D.C. 2007. Heterophenomenology reconsidered. Phenomenology and the Cognitive Sciences 6 (1): $247-270$.

Ginsburg, C. 2005. First-person experiments. Journal of Consciousness Studies 12 (2): 22-42.

Goldman, A. 1997. Science, publicity, and consciousness. Philosophy of Science 64: 525-545.

Goldman, A. 2004. Epistemology and the evidential status of introspective reports. Journal of Consciousness Studies 11 (7-8): 1-16.

Grzybowski, A., and P. Aydin. 2007. Edme Mariotte (1620-1684): Pioneer of neurophysiology. Survey of Ophthalmology 52 (4): 443-451.

Guzeldere, G. 1995. Consciousness: What it is, how to study it, what to learn from its history. Journal of Consciousness Studies 2 (1): 30-51.

Hacking, I. 1983. Representing and intervening. Cambridge: Cambridge University Press.

Hatfield, G. 2005. Introspective evidence in psychology. In Scientific Evidence: Philosophical Theories and Applications, ed. P. Achinstein, 259-286. Baltimore: John Hopkins University Press.

Harding, D.E. 1990/1999. Head off stress. London: The Sholland Trust.

Helmholtz, H.V. 1860/1925. Treatise on physiological optics (J. P. C. Southall, Trans. Vol. III). New York: Optical Society of America.

Hill, S.C. 2011. How to study introspection. Journal of Consciousness Studies 18 (1): 21-43.

Hohwy, J. 2011. Phenomenal variability and introspective reliability. Mind \& Language 26 (3): 261-286.

Horst, S. 2005. Phenomenology and psychophysics. Phenomenology and the Cognitive Sciences 4 (1): 1-21.

Hurlburt, R.T., Schwitzgebel, E. 2007. Describing inner experience?: Proponent meets skeptic. Cambridge: MIT Press.

Ihde, D. 2012. Experimental phenomenology: Multistabilities. Albany: SUNY Press. 
Irvine, E. 2012. Old problems with new measures in the science of consciousness. The British Journal for the Philosophy of Science 63 (3): 627-648.

Jack, A.I., and T. Shallice. 2001. Introspective physicalism as an approach to the science of consciousness. Cognition 79 (1): 161-196.

Julesz, B. 1964. Binocular depth perception without familiarity cues. Science 145 (3630): 356-362.

Kanizsa, G. 1976. Subjective contours. Scientific American 234: 48-52.

Koffka, K. 1935. Principles of Gestalt psychology. New York: Harcourt, Brace, \& World.

Köhler, W. 1947. Gestalt psychology. New York: Liveright.

Koksvik, O. 2015. Phenomenal contrast: A critique. American Philosophical Quarterly 52 (4): 321-334.

Kriegel, U. 2007. The phenomenologically manifest. Phenomenology and the Cognitive Sciences 6 (1-2): 115-136.

Kriegel, U. 2013. A hesitant defense of introspection. Philosophical Studies 165 (3): 1165-1176.

Loftin, R.W. 1990. Auras: Searching for the light. The Skeptical Inquirer 24 (4): 403-409.

Lutz, A., and E. Thompson. 2003. Neurophenomenology: Integrating subjective experience and brain dynamics in the neuroscience of consciousness. Journal of Consciousness Studies 10 (9-10): 31-52.

Lyons, W. 1986. The disappearance of introspection. Cambridge: MIT Press.

Masrour, F. 2011. Is perceptual phenomenology thin? Philosophy and Phenomenological Research 83 (2): 366-397.

Meketa, I. 2012. The false dichotomy between experiment and observation: The case of comparative cognition. Paper presented at the Philosophy of Scientific Experimentation 3, University of Colorado, Boulder, October 5-6.

Monson, C.K. 1993. A comment to suspend the introspection controversy. In Sampling Inner Experience in Disturbed Affect, ed. R.T. Hurlburt, 15-26. New york: Plenum Press.

Müller-Lyer, F.C. 1889. Optische urteilstäuschungen. Archiv für Anatomie und Physiologie. Physiologische Abteilung 2: 263-270.

Nahmias, E.A. 2002. Verbal reports on the contents of consciousness: Reconsidering introspectionist methodology. Psyche, 8(21), http://journalpsyche.org/files/0xaab0.pdf.

Nanay, B. 2012. Perceptual phenomenology. Philosophical Perspectives 26 (1): 235-246.

Nisbett, R.E., and T.D. Wilson. 1977. Telling more than we can know: Verbal reports on mental processes. Psychological Review 84: 231-359.

Palmer, S.E. 1999. Vision science: Photons to phenomenology. Vol. 1. Cambridge: MIT press.

Parker, W.S. 2009. Does matter really matter? Computer simulations, experiments, and materiality. Synthese 169 (3): 483-496.

Peels, R. 2016. The empirical case against introspection. Philosophical Studies 173 (9): 2461-2485.

Piccinini, G. 2003. Data from introspective reports: Upgrading from common sense to science. Journal of Consciousness Studies 10 (9-10): 141-156.

Piccinini, G. 2009. First-person data, publicity, and self-measurement. Philosophers Imprint 9 (9): 1-16.

Piccinini, G. 2010. How to improve on heterophenomenology: The self-measurement methodology of firstperson data. Journal of Consciousness Studies 17 (3-4): 84-106.

Piccinini, G. 2011. Scientific methods must be public, and descriptive experience sampling qualifies. Journal of Consciousness Studies 18 (1): 102-117.

Price, D.D., and J.J. Barrell. 2012. Inner experience and neuroscience: Merging both perspectives. Cambridge: MIT Press.

Prinz, J. 2013. Siegel's get rich quick scheme. Philosophical Studies 163 (3): 827-835.

Ramm, B.J. 2016. Dimensions of reliability in phenomenal judgment. Journal of Consciousness Studies 23 (3-4): 101-127.

Ramm, B.J. 2017. Self-Experience. Journal of Consciousness Studies 24 (11-12): 142-166.

Robinson, W.S. 2005. Thoughts without distinctive non-imagistic phenomenology. Philosophy and Phenomenological Research 70: 534-561.

Robinson, J.O. 2013. The psychology of visual illusion. Mineola: Courier Dover Publications.

Rock, I. 1975. Introduction to perception. New York: Macmillan.

Schwitzgebel, E. 2011. Perplexities of consciousness. Cambridge: MIT Press.

Shear, J., and F.J. Varela, eds. 1999. The view from within: First-person approaches to the study of consciousness. Thorverton: Imprint Academic.

Siegel, S. 2007. How can we discover the contents of experience? The Southern Journal of Philosophy 45 (S1): 127-142.

Siegel, S. 2011. The contents of visual experience. Oxford: Oxford University Press.

Siegel, S. 2013. Replies to Campbell, Prinz, and Travis. Philosophical Studies 163 (3): 847-865.

Siewert, C. 1998. The significance of consciousness. Princeton: Princeton University Press. 
Smithies, D. 2013. On the unreliability of introspection. Philosophical Studies 165 (3): 1177-1186.

Solomon, G.E.A. 1990. Psychology of novice and expert wine talk. The American Journal of Psychology 103 (4): $495-517$.

Tiles, J.E. 1993. Experiment as intervention. The British Journal for the Philosophy of Science 44 (3): $463-$ 475.

Tse, P.U. 2005. Voluntary attention modulates the brightness of overlapping transparent surfaces. Vision Research 45 (9): 1095-1098.

Varela, F.J. 1996. Neurophenomenology: A methodological remedy for the hard problem. Journal of Consciousness Studies 3 (4): 330-349.

Velmans, M. 1991. Is human information processing conscious? Behavioral and Brain Sciences 14 (4): 651726.

Velmans, M. 2000. Understanding consciousness. London: Routledge.

Velmans, M. 2007. Heterophenomenology versus critical phenomenology. Phenomenology and the Cognitive Sciences 6 (1-2): 221-230.

Vicario, G.B. 1993. On experimental phenomenology. Advances in Psychology 99: 197-219.

Watson, J.B. 1913. Psychology as the behaviorist views it. Psychological Review 20 (2): 158-177.

Watzl, S., and W. Wu. 2012. Perplexities of Consciousness, by Eric Schwitzgebel. Mind 121 (482): 524-529.

Wertheimer, M. 1912. Experimentelle studien über das sehen von bewegung. Zeitschrift für Psychologie 61 (1): $161-265$.

Woodward, J. 2003. Experimentation, causal inference, and instrumental realism. In The Philosophy of Scientific Experimentation, ed. H. Radder, 87-118. Pittsburgh: University of Pittsburgh Press. 